\title{
(t)
}

\section{VIOLÊNCIA DE GÊNERO, POLÍTICAS PÚBLICAS PARA O SEU ENFRENTAMENTO E O PAPEL DO SERVIÇO SOCIAL}

\author{
GENDER VIOLENCE, PUBLIC POLICIES FOR ITS \\ CONFRONTING AND THE ROLE OF SOCIAL SERVICE
}

\section{Teresa Kleba Lisboa'}

\section{Resumo}

Neste artigo, apresenta-se a temática da violência de gênero, com seus diferentes desdobramentos: violência doméstica, violência contra a mulher, violência intrafamiliar, entre outras. A violência de gênero tem sido definida como uma relação de poder e de permanente conflito, principalmente no lócus familiar, demandando atendimento, encaminhamentos, orientação, informação, recursos e capacitação por parte dos profissionais que trabalham com essa questão, particularmente assistentes sociais, psicólogos, profissionais da área da saúde bem como os da área jurídica. Reflete-se sobre a complexidade das questões que envolvem o enfrentamento da violência contra a mulher chamando a atenção para o papel do Estado na garantia de políticas públicas que perpassam diferentes áreas. Ressalta-se que o papel das/dos Assistentes Sociais é fundamental junto a essa questão. Questiona-se por que a maioria dos cursos de Serviço Social (no Brasil) não insere em seus currículos conteúdos que preparam os profissionais para trabalhar com situações de violência. Por fim, propõe-se um trabalho interdisciplinar destacando o papel do Serviço Social no atendimento das usuárias.

Palavras-chave: Serviço Social. Violência de Gênero. Políticas Públicas. Interdisciplinaridade.

1 Professora do Departamento de Serviço Social e do Programa de Pós-Graduação Interdisciplinar em Ciências Humanas da Universidade Federal de Santa Catarina, Florianópolis/SC. E-mail: tkleba@gmail.com. 


\section{temporalis}

\section{ABSTRACT}

In this article, we present the issue of gender violence, with its various outcomes: domestic violence, violence against women, intrafamiliar violence and others. Gender violence has been defined as a relationship of power and permanent conflict, especially in family locus, requiring care, referrals, counselling, education, resources and training from professionals who work with this question, particularly social workers, psychologists, health professionals and the legal department. We reflect about the complexity of the issues surrounding confronting violence against women calling attention to the State's role in ensuring public policies that underlie different areas. We emphasize that the role of social workers is essential along this issue. It is questioned why most courses of Social Service (in Brazil) do not insert content into their curricula that prepare professionals to work in situations of violence. Finally, we propose an interdisciplinary work highlighting the role of social service in the attendance of users.

Keywords: Social Service. Gender Violence. Public Policy. Interdisciplinary.

Submetido em 11/02/2014

Aceito em 16/07/2014

\section{INTRODUÇÃO}

As/os profissionais de Serviço Social, uma categoria formada por $95 \%$ de profissionais do sexo feminino e que no seu cotidiano de intervenção atende predominantemente (usuárias) mulheres, têm se defrontado com uma crescente demanda de situações perpassadas pelas questões de gênero, imbricadas com as questões de classe, raça/etnia, que caracterizam exclusão, discriminação, exploração, opressão, desigualdade social, relações de poder, de violência, entre outras. Tais situações assumem materialidade através da violência sexual e de gênero; da gravidez indesejada e do aborto provocado e criminalizado; da ausência de condições das mulheres responsáveis por prover suas famílias; do abandono e da violência contra mulheres idosas; da discriminação das mulheres no mundo do trabalho; do assédio moral; da luta pela aposentadoria para as donas de casa e para as trabalhadoras rurais; das precárias condições em que vivem as mulheres encarceradas; da discriminação em função da cor ou da orientação sexual; dos pleitos pela adoção por casais homoafetivos, entre outras formas de violência. De forma pulverizada, 
quando não isolada, algumas/uns profissionais de Serviço Social têm se aproximado dos estudos de gênero, étnico-raciais e da diversidade sexual, insistindo na importância da transversalidade dessas categorias na mediação teórica sobre a análise das práticas que surgem das demandas no cotidiano.

Enquanto Assistente Social - identificada na academia com a linha dos estudos feministas e na militância, como integrante de espaços da esfera pública: Conselho Municipal dos Direitos da Mulher, Fórum Catarinense de Mulheres, ambos com a função de sugerir políticas públicas com equidade de gênero -, propomos neste artigo ${ }^{2}$ discutir a complexidade que envolve o conceito "violência de gênero", remetendo às questões que abrangem o enfrentamento da violência contra a mulher e chamando a atenção para o papel do Estado na garantia de políticas públicas que perpassam diferentes áreas; ressaltar que o papel das/dos Assistentes Sociais é fundamental junto a essa questão; indagar por que os cursos de Serviço Social não inserem em seus currículos conteúdos que preparam os profissionais para trabalhar com situações de violência; e propor um trabalho interdisciplinar no atendimento das usuárias.

\section{O SERVIÇO SOCIAL E A QUESTÃO DA VIOLÊNCIA DE GÊNERO}

No panorama das novas interfaces que se apresentam para a profissão, a violência de gênero tem se constituído gradativamente como campo de intervenção do Serviço Social. Nos últimos anos, as lutas travadas pelos movimentos feministas alcançaram conquistas em relação aos direitos das mulheres e passaram a visibilizar a questão da violência, tirando-a do espaço privado para transformá-la em política pública.

Nesse cenário de avanços, as/os Assistentes Sociais têm sido chamadas/os para trabalhar com situações de violência em instituições como: Centros de Referência em Atendimento às Mulheres em Situação de Violência (CREMVs), Juizados de Violência Doméstica e Familiar contra a Mulher, Centros de

2 Este artigo é uma versão ampliada e atualizada do trabalho apresentado no II CONINTER - Congresso Internacional Interdisciplinar em Sociais e Humanidades, que aconteceu em Belo Horizonte, de 8 a 11 de outubro de 2013. 


\section{temporalis}

Referência Especializados em Assistência Social (CREAS), mais especificamente no Serviço de Atendimento Especializado a Família e Indivíduos (PAEFI); junto aos Protocolos da Violência, em Hospitais, Maternidades, Postos de Saúde, Delegacias, integrando a equipe interdisciplinar no Atendimento sociojurídico; às Práticas Forenses dos estudantes de Direito nas Universidades; aos Conselhos Tutelares e Conselhos dos Direitos das Mulheres, entre outros.

A complexidade que envolve o conceito "violência de gênero" aponta que, para além da força física, existem outros tipos de violência que se exercem por imposição social ou por pressão psicológica: a violência emocional, invisível, simbólica, econômica, entre outras, cujos efeitos produzem tanto ou mais danos do que a ação física. Velázquez (2006, p. 26) aponta que, de acordo com a Organização das Nações Unidas (1993), "Violência de Gênero é todo o ato de violência que tenha ou possa ter como resultado um dano ou sofrimento físico, sexual e psicológico para a mulher, inclusive as ameaças de tais atos, a coação ou a privação arbitrária da liberdade, tanto produzidas na vida pública como no espaço privado".

Para Susana Velázquez (2006), a violência de gênero nos conduz a abordá-la desde a perspectiva individual até a do coletivo. Leva-nos, também, a repensar os limites da ética e dos direitos humanos. Segundo a autora, violência de gênero engloba várias formas de violência: violência doméstica, violência contra a mulher, violência familiar ou intrafamiliar, violência conjugal, violência sexual (no interior da família e em diferentes âmbitos da comunidade), violência psicológica, patrimonial, tráfico de mulheres e de meninas para fins de prostituição etc. As temáticas mais específicas como o abuso sexual de crianças e adolescentes, maus-tratos infantis, incesto (violências exercidas especialmente pelo fato de serem mulheres) também estão incluídas nesse vasto "guarda-chuva" que abriga a diversidade de tipologias que cabem no conceito.

As diferentes formas de violência passam a ser publicizadas e evidenciadas a partir dos estudos feministas, o que permite afirmar que todas as formas de violência exercidas contra mulheres 
"compartem alguns elementos básicos que caracterizam a violência de gênero: a coerção, a intimidação, a ameaça, a coação, o abuso, a força, o controle e o poder" (VELÁZQUEZ, 2006, p. 224).

Apesar de as evidências apontarem dados que são tornados públicos através de registros, as violências cotidianas que ocorrem entre "quatro paredes", no interior das famílias, nos espaços de trabalho, de estudo, nos consultórios e nas ruas tendem a ser silenciadas ou invisibilizadas. Grande parte da sociedade considera que a violência de gênero é algo natural, que mulher é culpada pelo mal de que padece, interessando-se pelos fatos somente quando estes são veiculados como manchetes de jornais ou crônicas policiais. Portanto, explicitar as diferentes formas de violência, nomeá-las (o que não se nomeia não existe) e torná-las visíveis, propondo políticas públicas para o seu enfrentamento, também é tarefa para as/os profissionais de Serviço Social, em que nos incluímos.

Em artigo recente 3 , ponderamos que, ao longo da história da profissão, o Serviço Social permaneceu distante das lutas mais significativas dos movimentos feministas, o que configura um desencontro e possível desconhecimento por parte dos estudantes e profissionais sobre os estudos feministas e as questões de gênero. Um grande número de Assistentes Sociais ainda tem dificuldade de identificar-se com o feminismo em função de uma concepção negativa atribuída ao conceito, ou seja, uma série de estereótipos relacionados a uma época em que "feminismo" era sinônimo de "um grupo de mulheres mal amadas, rebeldes e separatistas", consequentemente, mal vistas pela sociedade em geral.

É comum as profissionais interiorizarem características funcionais (funções ou papéis atribuídos a elas pela sociedade) e se converterem em defensoras da "identidade feminina": feminina, sim; feminista, não! Nesse sentido, consideramos que as reflexões acadêmicas a partir da perspectiva de gênero têm contribuído para repensarmos como vêm sendo abordadas tradicionalmente,

3 LISBOA, Teresa Kleba. Gênero, Feminismo e Serviço Social: encontros e desencontros ao longo da história da profissão. Katálysis, v. 13, n. 01, p. 66-75, jan./jun. 2010. 


\section{temporalis}

nos currículos dos cursos de Serviço Social, as noções de feminismo, cidadania, desigualdade, diversidade, relações de gênero, equidade de gênero, entre outras. O debate em torno dessas categorias tem crescido nos últimos anos, como podemos perceber a partir de publicações recentes. Esse tema, porém, ainda é tratado nos currículos como "uma das especificidades do campo profissional", como uma disciplina optativa, e não como ferramenta teórica transversal que possa contribuir para a compreensão das relações sociais marcadas pela dominação-exploração. Ocorre certo preconceito em relação ao tema que é colocado no pacote da pós-modernidade, do culturalismo, de modo a desqualificar o debate.

É importante lembrar que as relações de gênero fazem parte do cotidiano de todas as pessoas, acontecem em todas as instâncias e em todos os níveis sociais. Por esse motivo, essa abordagem deve estar integrada a uma análise global da sociedade e ser pensada em termos dinâmicos, pois repousa em antagonismos e contradições. Lembramos que embora o conceito de gênero tenha ganhado força e destaque enquanto instrumento de análise das condições das mulheres ele não deve ser utilizado como sinônimo de "mulher". O conceito é usado tanto para distinguir e descrever as categorias mulher e homem como para examinar as relações estabelecidas entre ambos.

Pensar as questões raciais, sociais e étnicas, juntamente com as categorias de classe e de gênero, tornou-se um eixo fundamental para as defensoras do feminismo latino-americano, como Maria Luiza Femenías (2007), que sugere uma releitura (uma tradução) das teorias eurocêntricas, "ressignificando-as" para as nossas questões específicas. A realidade do nosso país é "singular”, fundada em três raízes populacionais: a autóctone indígena, a europeia branca e a negra. Essa situação peculiar demanda "trazer a tona a nossa história de deslocamentos, reacomodações, resistências, identidades mestiças" (FEMENÍAS, 2007, p. 16), requer uma política de identidade, uma abertura para a diversidade étnica e cultural; intersecção entre as categorias gênero, classe, raça/etnia. Desse modo, sugere-se que a formação profissional das/dos Assistentes Sociais possa incluir a apropriação de uma metodologia que articule a dimensão teórica e a interventiva, 
construída a partir do entendimento de que classe, gênero, raça/ etnia estruturam as relações sociais marcadas historicamente.

Reconhecemos que o Serviço Social tem muito a contribuir com o conhecimento voltado para a elaboração, gestão e operacionalização das políticas públicas, com compromisso de promover a equidade de gênero. O cotidiano de intervenção profissional nos possibilita conhecer a realidade multifacetada das mulheres em seus diferentes contextos, principalmente as que se encontram em situação de violência, e ter acesso a dados que poderão contribuir para a construção do aporte teórico da área, o qual, por sua vez, pode subsidiar as políticas públicas com perspectiva de gênero.

\section{VIOLÊNCIA DE GÊNERO - UMA QUESTÃO DE PODER E DE DOMINAÇÃO}

Partimos do pressuposto de que a violência é inseparável da noção de gênero porque se baseia e é praticada na e pela diferença social entre mulheres e homens. Incluir a noção de gênero em uma definição de violência é imprescindível, pois, de acordo com Célia Amorós (1995), o gênero constitui a construção mesma da hierarquização patriarcal. A desigualdade entre homens e mulheres é a chave da discriminação sexista e a origem de toda a violência de gênero.

Para Velázquez (2006, p. 27), “a palavra violência indica uma maneira de proceder que ofende e prejudica a alguém mediante o uso exclusivo da força. Deriva de vis, força”. Entretanto, não podemos omitir outras formas de violências exercidas por "imposição social”, ou por pressão psicológica, cujos efeitos produzem tanto ou mais dano do que a força física. Essas diferentes formas de violência são explicitadas a partir dos estudos de gênero que permitem identificá-las e vinculá-las com pautas culturais e sociais diferenciadas para homens e mulheres.

Coincidindo com os significados de força e coerção, para Lori Heise (1994 apud HUACUZ ELIAS, 2009, p. 14), violência contra as mulheres é considerada como "todo o ato de força física ou verbal, coerção ou privação ameaçadora para a vida, dirigida a mulheres ou meninas, que cause dano físico ou psicológico, 


\section{temporalis}

humilhação ou privação arbitrária de liberdade e que perpetue a subordinação feminina". Essa definição explica alguns pontos centrais, de acordo com Maria Guadalupe Huacuz Elias (2009, p. 14), para compreender a violência identificada em uma análise empírica: a) especifica o sujeito a quem se dirige a violência (mulher ou menina); b) as características da ação (coerção ou privação); c) o tipo de dano que pode resultar a ação (psicológica, física, econômica ou sexual); d) a pretensão do ato (perpetuar a subordinação das mulheres).

A violência contra as mulheres ocorre em um contexto sócio-histórico de uma sociedade patriarcal hierárquica, de múltiplas opressões, o que é confirmado por Diana Ferrer (2011, p. 65): "nas relações de poder existentes no interior das famílias e particularmente nas relações de intimidade, a violência se converte em uma ferramenta de poder e controle social para manter e perpetuar os interesses dos homens frente aos das mulheres". Segundo essa perspectiva, a violência contra as mulheres se dá predominantemente no espaço doméstico e é perpetrada principalmente por homens. Todavia, é importante mencionar que a "violência doméstica" não exclui as mulheres como agentes contra outras mulheres e meninas com menor poder de hierarquia dentro do espaço temporal doméstico. Isso significa que a "protagonista" da violência eventualmente pode ser uma mulher jovem contra uma mulher idosa, a irmã mais velha contra as mais novas, violência entre casais homoafetivos ou as sogras que maltratam as noras (e vice-versa), entre outros exemplos. Constata-se, porém, uma enorme disparidade entre as situações de violência cometidas entre mulheres (somente $8 \%$ dos casos), contrastando com $92 \%$ de atos de violência desferidos por homens contra mulheres.

Uma das modalidades de violência doméstica é a violência conjugal, a qual, de acordo com Irene Casique (2007, p. 231), ocorre devido às desigualdades de poder que se estabelecem entre um casal que mantém relações erótico-afetivas. A violência conjugal inclui situações de abuso que se produzem de forma cíclica e com intensidade crescente entre duas pessoas que estabelecem relações conjugais. 
Todas essas modalidades de violência trazem implícita uma desigualdade de gênero. Integrando as perspectivas apresentadas enunciadas até agora, ampliamos a definição de violência de gênero com base em Velázquez (2006, p. 29), para a qual: "Violência de gênero abarca todos os atos mediante os quais se discrimina, ignora, submete ou subordina as mulheres nos diferentes aspectos de sua existência. É todo ataque material ou simbólico que afeta sua liberdade, segurança, intimidade e integridade moral e/ou física".

Ressaltamos que os estudos de gênero têm contribuído para decifrar o inquietante questionamento: por que, ao longo da história, a diferença sexual tem sido o fundamento da subordinação feminina, consequentemente, o fundamento da desigualdade social?

Para Joan Scott (1995), a categoria gênero se emprega para designar as relações sociais entre os sexos. A autora afirma que não existe um mundo das mulheres separado de um mundo dos homens. "A informação sobre as mulheres é necessariamente informação sobre os homens, um estudo implica o outro. Este uso insiste em que o mundo das mulheres é parte do mundo dos homens, criado nele e por ele. Este uso rejeita a utilidade interpretativa de esferas separadas" (SCOTT, 1995, p. 80).

O central de sua definição de gênero é a "conexão" entre duas ideias: "o gênero é um elemento constitutivo das relações sociais baseadas nas diferenças que distinguem os sexos e o gênero é uma forma primária de relações de poder" (SCOTT, 1995, p. 86).

Para a autora, o gênero é o campo primário dentro do qual e por meio do qual se articula o poder, ressaltando que o processo histórico social também é composto por processos políticos, os quais assumem diferentes significados, conforme os sujeitos e as instituições sociais vão Ihes atribuindo. Logo, os estudos sobre as relações de gênero lançarão novos olhares sobre velhas questões, fazendo emergir uma "nova história", redefinindo e reestruturando as relações entre homens e mulheres, sujeitos múltiplos que requerem concepções de análise plurais, ou seja, de classe, de raça/etnia e de gênero. 


\section{temporalis}

Ao analisar a dominação masculina, Pierre Bourdieu (2003) argumenta que a lógica do gênero é uma lógica de poder e de dominação, é a forma paradigmática de "violência simbólica", ou seja, aquela violência exercida sobre um agente social com sua cumplicidade e seu consentimento. Para o autor, a cultura marca os seres humanos com o gênero e o gênero marca a percepção do social, do político, do religioso, do cotidiano. A lógica de gênero também funciona como uma instituição inscrita por milênios na objetividade das estruturas sociais e na subjetividade das estruturas mentais. Diz o autor que a ordem social masculina está tão profundamente arraigada que não requer justificação: se impõe a si mesma como autoevidente e é tomada como "natural”, graças ao acordo quase perfeito e imediato que obtém tanto das estruturas sociais quanto das estruturas cognitivas inscritas nos corpos e nas mentes.

Por outro lado, em sendo a violência de gênero uma forma de afirmar o poder e o controle dos homens sobre as mulheres, Foucault (1988) nos adverte que onde há poder há resistência, o que remete ao apelo às mulheres sobreviventes da violência para produzir maneiras alternativas de poder e resistência, agindo como "sujeitos livres", uma vez que o autor diferencia relações de poder e de dominação. Nesta, a capacidade de agir deixa de existir por se tratar de uma relação fixa e assimétrica, enquanto nas relações de poder as ações se voltam para o outro reconhecido como sujeito. Portanto, para o autor, “[...] lá onde há poder, há resistência, [...] as relações de poder não podem existir senão em função de uma multiplicidade de pontos de resistência; elas (as resistências) são o outro termo das relações de poder" (FOUCAULT, 1988, p. 91).

Essa correlação de forças (entre poder e formas de resistência) está presente em todo o contexto sociocultural, incluindo as instituições hierárquicas e patriarcais, as normas culturais sexistas e racistas, a forma como fomos socializados, com base em uma perspectiva de gênero que aprova e legitima a violência contra as mulheres aliada à interseccionalidade das múltiplas formas de opressão que as mulheres sofrem na sociedade, pelas questões de gênero, classe e raça/etnia. 
Nesse sentido, os estudos feministas têm sugerido estratégias de intervenção contra a violência doméstica, que vão desde promover mudanças nas normas sociais e culturais através da educação, criar grupos de conscientização, apoio e empoderamento, tanto para homens (agressores ou não) quanto para mulheres (em situação de violência ou não), passando por campanhas através dos meios de comunicação e reformulação da legislação até a criação de programas de capacitação para técnicos que trabaIham com a questão da violência.

Para desconstruir essa estrutura simbólica de poder e dominação dos homens sobre as mulheres repassada durante séculos através das instituições, os estudos feministas nos convidam a adotar uma "perspectiva de gênero" em nossas formas de pensar e agir, nos processos de intervenção profissional, partindo de uma concepção crítica da "visão androcêntrica" da humanidade, que acabou por excluir metade do gênero humano dos espaços sociopolíticos. A perspectiva de gênero propõe lançar um novo olhar sobre a realidade a partir das mulheres e com as mulheres revolucionando a ordem dos poderes. Centra-se no reconhecimento da diversidade de gênero que implica a reconstrução de uma humanidade diversa e democrática.

A crescente incorporação da perspectiva de gênero na elaboração de políticas públicas, interpretações e diagnósticos tem permitido, conforme Marcela Lagarde (1996), a visibilidade das mulheres e da problemática que as envolve, assim como tem contribuído para os avanços na emancipação feminina. Levando em conta a atual situação de desigualdade em que se encontram as mulheres, consideradas cidadãs e sujeitos de direito, conclama-se o papel do Estado no enfrentamento dessa questão.

\section{O ENFRENTAMENTO DA VIOLÊNCIA CONTRA AS MULHERES COMO DEVER E RESPONSABILIDADE DO ESTADO}

A Convenção Interamericana para Prevenir, Punir e Erradicar a Violência contra a Mulher, mais conhecida como "Convenção de Belém do Pará”, ratificada pelo Brasil em 27 de novembro de 1995, destaca o direito de toda mulher a uma vida livre de violência, que compreende "o direito a ser livre de todas as formas de discriminação e o direito de ser valorizada e educada livre de padrões 


\section{temporalis}

estereotipados de comportamento e costumes sociais e culturais baseados em conceitos de inferioridade ou subordinação".

No capítulo III, a Convenção traz os deveres que devem ser assumidos pelos Estados, devendo ser levada em conta a situação da mulher vulnerável à violência por sua raça, origem étnica ou condição de migrante, de refugiada ou de deslocada. Entre outros, destacam-se os deveres do Estado: "Agir com o devido zelo para prevenir, investigar e punir a violência contra a mulher; [...] prestar serviços especializados apropriados à mulher sujeita à violência, por intermédio de entidades dos setores público e privado, inclusive abrigos, serviços de orientação familiar, quando for o caso $[\ldots]$ "..".

Em 2003, foi instituída no Brasil a Secretaria Especial de Políticas Públicas para Mulheres (SPM), atualmente com status de Ministério, constituindo-se em um marco na história de luta das mulheres brasileiras, na medida em que traçou como meta inserir a igualdade de gênero como um tema transversal às políticas públicas. A partir dessa instância nacional, foram criados na esfera dos estados e municípios os Conselhos de Direitos das Mulheres e as Coordenadorias Especiais de Mulheres, responsáveis pela elaboração e articulação das políticas para mulheres, garantindo e fiscalizando programas, projetos que modificam as condições de vida das mulheres, oferecendo oportunidades de empoderamento e contribuindo para a equidade de gênero.

Um marco histórico na vida das mulheres foi a IV Conferência Mundial das Mulheres em Beijing (1995), que apontou como estratégia a defesa junto aos Estados da gender mainstreaming, conhecida como transversalidade de gênero nas políticas públicas, que preconiza a incorporação da melhoria do status das mulheres em todas as dimensões da sociedade - econômica, política, cultural e social.

Fruto de amplo debate em nível nacional que envolveu milhares de mulheres e resultado de um processo participativo que ocorreu através da realização de Conferências (municipais

4 A "Convenção de Belém do Pará" pode ser acessada no site da Comissão Interamericana de Direitos Humanos. Disponível em: <http://www.cidh.oas.org/ basicos/portugues/m.Belem.do.Para.htm>. 
e estaduais), o Plano Nacional de Políticas para as Mulheres de 2004, no capítulo IV, que trata do enfrentamento da violência cometida contra as mulheres, ressalta que

cabe ao Estado adotar uma política sistemática e continuada em diferentes áreas. A intervenção deve se caracterizar pela promoção e implementação de políticas públicas de responsabilidade dos governos federal, estaduais e municipais, constituindo uma rede de ações e serviços. As redes devem articular assistência jurídica, social, serviços de saúde, segurança, educação e trabalho. Os serviços e organizações que compõem as redes incluem: Delegacias Especializadas de Atendimento à Mulher, delegacias comuns, Centro de Referência, Defensorias Públicas da Mulher, Defensorias Públicas, Instituto Médico Legal, Serviços de Saúde, Polícia Militar, Corpo de Bombeiros, Casas Abrigos (BRASIL, PNPM, 2004, p. 2).

A Lei Maria da Penha (Lei n. 11.340) foi aprovada no Brasil em agosto de 2006 com o principal objetivo de representar um instrumento jurídico eficaz que contenha as disposições legais e mecanismos para coibir e prevenir a violência doméstica e familiar contra as mulheres. A referida Lei também traz aspectos conceituais e educativos, uma vez que se propõe a promover uma real mudança nos valores sociais da sociedade brasileira, que banaliza a violência que ocorre nas relações domésticas e familiares e legitima os padrões de supremacia masculina e subordinação feminina, aceitos pela humanidade durante séculos.

As principais inovações trazidas pela Lei 11.340 são: a) tipifica e define a violência doméstica e familiar contra a mulher como um crime; b) estabelece as formas de violência doméstica contra a mulher como sendo física, psicológica, sexual, patrimonial e moral; c) determina que a violência doméstica contra a mulher independe de orientação sexual; d) cria Juizados Especiais de Violência Doméstica e Familiar contra a Mulher, com competência cível e criminal para todas as questões; e) prevê um capítulo específico para o atendimento, pela autoridade policial, para os casos de violência doméstica contra a mulher; f) define que a mulher somente poderá renunciar perante o juiz; g) veda a 


\section{temporalis}

entrega da intimação ao agressor pela mulher; h) possibilita a prisão em flagrante; i) altera o Código de Processo Penal para possibilitar ao juiz a decretação da prisão preventiva, quando houver riscos à integridade física ou psicológica da mulher; j) determina que a mulher vítima de violência doméstica será notificada dos atos processuais, especialmente quanto ao ingresso e saída da prisão do agressor; I) determina que a mulher deverá estar acompanhada de advogado ou defensor em todos os atos processuais.

Preocupada com a lentidão dos encaminhamentos, no ano de 2007 (um ano após a sanção da Lei Maria da Penha), a Secretaria Especial de Políticas Publicas para Mulheres baixou um Decreto que obriga todos os Estados da Federação do Brasil a assinar o Pacto Nacional pelo Enfrentamento à Violência contra a Mulher (doravante denominado Pacto). O Pacto consiste num acordo federativo entre o governo federal e os governos dos estados e dos municípios brasileiros para o planejamento de ações que visem à consolidação da Política Nacional de Enfrentamento à Violência contra as Mulheres por meio da implementação de políticas públicas integradas em todo o território nacional.

O Pacto parte do entendimento de que a violência constitui-se em um fenômeno de caráter multidimensional, que requer a implementação de políticas públicas amplas e articuladas nas mais diferentes esferas da vida social, como na educação, no mundo do trabalho, na saúde, na segurança pública, na assistência social, entre outras.

Conforme documento intitulado "Pacto Nacional pelo Enfrentamento à Violência contra Mulheres" (SEPM, 2011, p. 12), seus eixos estruturantes são: 1) garantia da aplicabilidade da Lei Maria da Penha; 2) ampliação e fortalecimento da rede de serviços para mulheres em situação de violência; 3) garantia da segurança cidadã e acesso à Justiça; 4) garantia dos direitos sexuais e reprodutivos, enfrentamento à exploração sexual e ao tráfico de mulheres; 5) garantia da autonomia das mulheres em situação de violência e ampliação de seus direitos 5 .

5 Disponível em: <http://www.sepm.gov.br/publicacoes-teste/publicacoes/2011/ pacto-nacional $>$. 
A efetivação e implementação dessas políticas, porém, requer por parte dos agentes públicos o entendimento dos pressupostos analíticos (transversalidade de gênero) que embasam essa questão bem como a garantia da governabilidade, em três dimensões articuladas: a) vontade e decisão política que preconizem, junto aos planejadores, a garantia que o Estado (município) desenvolva políticas que incidam efetivamente sobre a desigualdade estrutural entre homens e mulheres; b) incorporação da perspectiva de gênero junto à prática dos gestores, que executam, monitoram e avaliam as políticas públicas nos níveis federal, estadual e municipal; c) disseminação de novos valores culturais e políticos junto à população, com vistas a uma cidadania inclusiva.

Pesquisas realizadas sobre a implementação da Lei Maria da Penha no Brasil ${ }^{6}$ constatam que esta não tem suprido as demandas de mulheres em situação de violência por vários motivos, dentre eles: falta de vontade política para priorizar a questão da violência contra as mulheres, que repercute diretamente na falta de estrutura física adequada; de recursos materiais e financeiros; de divulgação e informação sobre os serviços disponíveis; de profissionais especializados e de efetivo policial para atender as mulheres; e, principalmente, de articulação e interlocução entre os vários serviços que compõem a rede, em especial os da área jurídica.

Nesse sentido, sugerimos como estratégia que os profissionais que atuam na área da violência contra a mulher, a partir das demandas trazidas no atendimento cotidiano, possam trabaIhar de forma mais articulada e propor políticas públicas eficazes, definir orçamento no Plano Plurianual, garantindo recursos materiais, humanos e financeiros, pressionar os gestores para que deem prioridade a essa questão e solidificar e divulgar a rede de atendimento no enfrentamento dessa questão, trabalhando na perspectiva da interdisciplinaridade.

6 Conforme Relatório da Pesquisa: “Identificando entraves na articulação dos serviços de atendimento às mulheres vítimas de violência doméstica e familiar em cinco capitais", realizada pelo Observatório da Lei Maria da Penha - Observe, publicado em agosto de 2010. Disponível em: <www.observe.ufba.br>. 


\section{tempordils}

\section{O SERVIÇO SOCIAL INTEGRANDO A EQUIPE INTERDISCIPLINAR NO ATENDIMENTO ÀS MULHERES EM SITUAÇÃO DE VIOLÊNCIA}

Toda mulher em situação de violência que procura atendimento especializado - seja em uma Delegacia de Mulheres, em um Centro de Referência, seja junto ao Juizado Especial da Violência, à Defensoria Pública, ao Atendimento sociojurídico, às Universidades, aos Hospitais, aos Postos de Saúde, entre outros espera ser atendida por uma equipe de técnicos preparados, isto é, capacitados e com sensibilidade para atuar na área da violência.

A maioria das mulheres em situação de violência chega aos serviços que prestam atendimento com muita vergonha e grande dificuldade para falar sobre o seu padecimento. Entre as principais dificuldades mencionadas por Velázquez (2006), estão: a) não reconhecem que a situação de debilidade física e emocional em que se encontram é decorrente de um longo processo de violência pelo qual estão passando; b) consideram que se falarem o que acontece realmente com elas não serão levadas a sério; c) tentam justificar o agressor, dizendo que foi um momento de fraqueza, que ele não é uma pessoa má; d) experimentam intenso sentimento de vergonha, humilhação e autodepreciação por haverem sido violentadas pelo companheiro (marido), pai de seus filhos; e) desconhecem os seus direitos e as leis que oferecem proteção.

Para dar conta desse conjunto de dificuldades, a autora propõe uma "epistemologia convergente, na qual as diferentes ciências funcionem como uma unidade operacional que enriqueça o objeto de conhecimento e as técnicas de abordagem" (VELÁZQUEZ, 2006, p. 227). Nessa direção, cada profissional (Assistente Social, Psicóloga, Advogada, entre outras) delimitará o seu campo de conhecimento e definirá seu objeto de estudo, buscando formas de interação e intercâmbio com as demais integrantes da equipe. Essa postura vem ao encontro da complexidade que envolve o fenômeno da violência, incluindo as múltiplas formas pelas quais ela se apresenta, o que tem demandado uma perspectiva interdisciplinar e ao mesmo tempo interinstitucional. Ou seja, além de compartilhar saberes entre si, cada técnico necessitará ter informações adequadas e suficientes sobre a rede de atendimento disponível para encaminhar as situações de violência. 
É necessário que a situação apresentada pelas mulheres seja acolhida, qualificada e tratada com respeito e sigilo profissional. Em geral, as mulheres em situação de violência chegam para o atendimento com a subjetividade arrasada; quando se diz: "esta mulher foi violentada", significa que foi agredida na sua mais íntima identidade, naquilo que as constitui como pessoas humanas. As Assistentes Sociais (ou Psicólogas) são as profissionais que fazem a primeira abordagem, acolhem as mulheres, e através de uma "escuta social qualificada" realizam uma entrevista, geralmente, para saber a demanda e preencher o cadastro socioeconômico da usuária. Esse espaço de escuta é fundamental para que a mulher em situação de violência possa romper o silêncio imposto. É o tempo em que ela se sentirá segura frente a um profissional que transmite confiança, que acredita no que ela vai falar, que a respeita e a encoraja a expressar sentimentos que até então estavam guardados por medo, confusos, e que agora ela é capaz de ordenar e clarear.

Esse é o momento em que as profissionais poderão propor estratégias de enfrentamento e de resistência para as mulheres em situação de violência. Marcela Lagarde (1999) identifica quatro formas de as mulheres enfrentarem a violência: 1) assumindo a naturalização do domínio e da opressão; 2) resistindo e desobedecendo ao poder; 3) subvertendo a ordem familiar, conjugal, laboral e de todo o tipo com ações opostas e contrárias; 4) transgredindo, que é a síntese das três formas anteriores, mediante o estabelecimento de uma ordem própria, não definida pelas normas tradicionais.

Frente a esses tipos de enfrentamento, a/o profissional de Serviço Social poderá elaborar, juntamente com a mulher em situação de violência, um plano individual e/ou familiar de atendimento. Para tanto, deverão ser estabelecidas articulações entre as Redes de Serviços, a fim de que essa mulher (e provavelmente seus filhos) possa ser atendida de acordo com os Programas e Projetos definidos na Política de Assistência Social; acompanhar os desdobramentos das situações da cada usuária, articulando com as diferentes unidades dos Centros de Referência de Assistência Social (Especializados ou não) - CRAS ou CREAS - de cada região ou bairro, ou outras instâncias com as quais possam estabelecer 


\section{temporalis}

troca de informações, como, por exemplo, transferência de creche ou de escola da criança enquanto a mulher encontra-se em abrigamento (Casa Abrigo). Sempre que se fizer necessário, será realizada uma visita domiciliar, pois esta se configura como um instrumento significativo para conhecer a realidade na qual vive a mulher, principalmente em processos que demandam o trabalho com a família, ou quando envolvem a guarda de crianças, exigindo um melhor acompanhamento da situação com estudo sociofamiliar.

Orientações básicas sobre os seus direitos poderão ser dadas pela(o) profissional de Serviço Social, bem como em relação aos diferentes tipos de violência e suas respectivas penalidades; à importância de fazerem a denúncia e efetuarem um Boletim de Ocorrência; aos mecanismos de proteção previstos na Lei Maria da Penha, esclarecendo as opções de encaminhamento para as diferentes Instituições da Rede Socioassistencial. Instrumentais Técnico-Operativos, como "Oficinas com Mulheres em situação de violência", poderão ser utilizados, bem como trabalhos com grupos junto aos Centros de Referência em Assistência Social (CRAS); divulgação de informações sobre a questão da violência através de folders e cartilhas, contendo: os locais que oferecem atendimento; explicação a respeito dos direitos das mulheres e dos mecanismos de proteção previstos na Lei Maria da Penha; e orientação para prevenir os desagravos e humilhações, entre outros aspectos.

A/o profissional da área da Psicologia também acolherá essa mulher com uma escuta qualificada e poderá ajudá-la a buscar alternativas que permitam solucionar a violência da qual está sendo vítima. De acordo com Velázquez (2006), a experiência clínica permite identificar três tipos de sentimentos nas mulheres que sofrem violência: sentimento de desamparo; sensação de estar em perigo permanente; sentir-se diferente das demais pessoas à sua volta. Para a autora, esses sentimentos surgem, geralmente, pela dor e pela impotência de não poder transformar o que passou, deixando marcas no corpo, nos afetos e na vida cotidiana. Cabe aos profissionais de Psicologia: fortalecer a autoestima das mulheres, para que possam tomar as decisões acertadas em relação a suas vidas, resolver conflitos de forma pacífica 
e caminhar em busca do empoderamento. Ainda, enfocar o reinício de uma vida livre de violência, através do rompimento de esquemas tradicionais e papéis estereotipados, incentivar a participação em grupos ou atividades sociais, a saída da dependência econômica e emocional, derivadas principalmente de uma cultura sustentada na desigualdade de gênero. Sempre que necessário, a mulher em situação de violência será convidada a receber tratamento psicoterapêutico, conforme os casos, incluindo também os filhos.

A/o profissional da área jurídica (Direito) oferece as alternativas legais que permitem as mulheres solucionarem seu problema de violência por meio da aplicação das leis. Procederá à orientação jurídico-social necessária e ao encaminhamento para a Defensoria Pública, Juizado Especial da Violência, Ministério Público, entre outras atribuições. A/o profissional de Direito pode orientar, ainda, em relação à forma correta de efetuar a denúncia, bem como esclarecer sobre as penas previstas para os companheiros que cometeram agressão, explicar que ela pode valer-se das medidas protetivas se estiver em situação de violência severa, que agora está vigorando o mandato de apreensão e busca do indivíduo que cometeu crime, enfim, estabelecer articulação interinstitucional com os demais órgãos que garantem os direitos dessa mulher.

Por sua vez, as/os profissionais da área da saúde também são demandadas/os nos Institutos Médicos Legais para a realização do exame de corpo delito e, principalmente, junto aos Postos de Saúde e atendimentos hospitalares, onde exercem importante papel no processo de identificação dos sintomas decorrentes da violência de gênero, que quase sempre são confundidos com as doenças consideradas "específicas de mulheres", como depressão, problemas no aparelho ginecológico, dentre outros.

É importante que a equipe interdisciplinar elabore e proponha um "Protocolo da Violência", para que as situações de violência contra a mulher sejam tratadas de forma articulada por uma Rede de Serviços, ocorrendo a intersetorialidade entre os serviços oferecidos pelas instituições que integram as políticas públicas municipais, entre elas, a saúde, educação, trabalho, habitação, 


\section{temporalis}

assistência social. Fazem parte dessa rede as Secretarias Municipais (Saúde, Educação, Habitação etc.), os Conselhos de Direito e todas as instituições conveniadas ao município vinculadas à questão da violência como: as Delegacias de Mulheres, O Centro de Referência no Atendimento a Mulheres em Situação de Violência (CREMV), a Casa de Passagem, as Casas de Proteção ou Abrigos para Mulheres em situação de violência severa ou ameaçadas de morte, o Disque Denúncia, o Protocolo de Atenção às Vítimas de Violência Sexual, os Hospitais, o Instituto Médico Legal, o atendimento sociojurídico nas universidades, as Defensorias Públicas, o Balcão da Cidadania, o Centro de Atendimento Psicológico (CAPs), o Centro de Reabilitação e Tratamento de Adictos (CRETA), o Instituto Nacional de Seguridade Social (INSS) e demais redes associadas às políticas públicas municipais. Uma intervenção em rede pode ampliar a autonomia dos sujeitos envolvidos, extrapolando a ação individual do profissional para com as usuárias e seus filhos. Um Benefício Eventual de Assistência Social (BEAS) poderá ser repassado para as mulheres que necessitam sair do espaço doméstico, em função da violência, e não têm como sobreviver.

Reuniões com a equipe interdisciplinar: assistentes sociais, psicólogos, advogados e, eventualmente, médicos, enfermeiros (do Instituto Médico Legal ou de outra unidade de saúde) e policiais envolvidos nas situações de violência pelas quais as mulheres estão passando são decisivas para o encaminhamento correto das situações. É muito importante estabelecer uma aliança de trabalho entre os integrantes da equipe que acompanham a mesma situação com o objetivo de analisarem o mesmo caso, ouvirem os diferentes pareceres ou laudos de seus colegas, socializarem os dados (diagnóstico), a fim de que os encaminhamentos possam ser realizados da maneira mais correta possível.

O que pode acontecer no interior de uma equipe multidisciplinar é uma disputa pela hegemonia sobre o poder e o saber, em que uma das áreas se coloca em posição hierarquicamente superior, pretendendo impor um tipo de conhecimento ou se fechando para as singularidades da contribuição de um campo teórico, como, por exemplo, os estudos de gênero. O trabalho interdisciplinar somente é possível se os profissionais das diferentes áreas exercitarem a humildade e considerarem a interdisciplinaridade como uma coexistência pacífica enriquecedora, em que uma 
profissão não desfaz a outra, mas sim absorve a especificidade do seu saber, com vistas a se complementarem mutuamente. A interdisciplinaridade fortalece os laços de solidariedade, exercita a convivência e a cooperação, respeita os diferentes saberes e permite a convergência destes em prol de um mesmo objetivo, que é a luta pelo fim da violência contra as mulheres.

\section{CONSIDERAÇÕES CONCLUSIVAS}

Procuramos mostrar neste artigo que as/os profissionais de Serviço Social estão sendo demandadas/os, cada vez mais, para atuarem junto a instituições que trabalham com a violência de gênero. Para que a intervenção desses profissionais seja reconhecida e valorizada, é necessário que o processo de formação inclua conhecimentos específicos relacionados a essa área, ou seja, que as/os Assistentes Sociais possam se interessar pelos estudos feministas, questões de gênero, étnico-raciais, construção de identidade e diversidade sexual, insistindo na importância da transversalidade dessas categorias na mediação teórica sobre as demandas que surgem no cotidiano de suas práticas.

Ressaltamos que, nos últimos 30 anos, o movimento feminista lutou para o reconhecimento da "violência de gênero" pela via do Judiciário e que os resultados alcançados são parte de uma importante estratégia política. A pressão organizada pelos movimentos feministas teve um papel fundamental em todo o processo de elaboração de leis e das propostas de políticas públicas que dispomos até o presente momento, para enfrentar e, sobretudo, coibir a violência doméstica e familiar contra a mulher. $\mathrm{O}$ feminismo tem se destacado pelo seu constante questionamento em relação às diferenças sociais, lutando pela igualdade com respeito às diferenças e reivindicando o reconhecimento social da desigualdade de gênero. O feminismo também tem como pressuposto ético-político denunciar que um conjunto de suposições que a sociedade definiu como "natural" (por exemplo, a heterossexualidade e a maternidade) engendra práticas opressivas e discriminatórias, causando sofrimento para as pessoas que fogem do padrão de "normalidade" estabelecido.

Trabalhar com a temática da violência de gênero bem como com políticas públicas para mulheres requer, por parte dos profissionais, 


\section{temporalis}

gestores, agentes públicos e juristas, a compreensão dos pressupostos analíticos que fundamentam essa questão. Demanda a incorporação de uma perspectiva que se baseia na equidade de gênero, ou seja, a elaboração de uma nova matriz (transversalidade de gênero) que oriente a visão dos poderes (político, institucional e administrativo), e um compromisso em assumir a responsabilidade no que concerne à superação das assimetrias de gênero entre as diferentes esferas de governo. Para tanto, é necessário:

- Destinar recursos para a implementação da Lei Maria da Penha, por meio da dotação de orçamento nos Planos Plurianuais dos Governos;

- Promover cursos de capacitação em direitos humanos e violência de gênero para os policiais e funcionários que trabalham com a questão da violência, seja junto a Delegacias e Centros de Referência, seja em instituições parceiras;

- Criação de mais "Delegacias" especializadas no atendimento de mulheres em situação de violência. Destinação de recursos, infraestrutura, equipamentos adequados;

- Criação de Centros de Reeducação e Reabilitação para agressores;

- Garantir os conteúdos que contemplem o enfoque de gênero e violência de gênero nas escolas e cursos universitários, principalmente nos cursos de Direito.

As políticas públicas que garantem a autonomia pessoal e econômica das mulheres e são relevantes para a Secretaria de Assistência Social, Secretaria da Saúde, Secretaria da Educação, entre outras, estão previstas enquanto atendimento às mulheres em situação de violência, na Lei Maria da Penha.

É importante criar programas para adolescentes e jovens, para que as novas gerações possam adotar modelos relacionais com base no respeito aos direitos das pessoas, nas responsabilidades individuais e nas diferenças. As esferas governamentais devem adotar uma perspectiva de gênero na condução de suas políticas, e o público deve exigir que os meios de comunicação, rádio, televisão, jornais e revistas, assumam o compromisso com o combate à violência, mudando a imagem que formam sobre as mulheres, que reforça a discriminação e a visão da mulher como objeto. 
A perspectiva de gênero exige uma nova postura acerca da visão de mundo, dos valores e do modo de vida, ou seja, coloca em crise a legitimidade do mundo patriarcal. Ela nos permite compreender que as relações de desigualdade e iniquidade entre gêneros é um produto da ordem social dominante e das múltiplas opressões de classe, raça, etnia e geração que se exercem sobre as mulheres e configuram uma sobreposição de domínio.

Reconhecemos que a incorporação do debate sobre a equidade de gênero nas políticas públicas no Brasil é resultado de um longo processo social e político de participação, sustentado em grande medida pela visibilidade e legitimidade que o movimento de mulheres tem alcançado nos últimos trinta anos, pelo tipo e pela qualidade da produção de conhecimento a respeito da temática das relações de gênero bem como pela resistência das mulheres no cenário político e social como sujeitos sociais.

Convidamos as/os profissionais de Serviço Social a se engajarem nas lutas feministas, a fim de que, em conformidade com nosso Projeto Ético-Político, contribuamos para que as mulheres possam ter uma vida livre de violência!

\section{REFERÊNCIAS}

AMORÓS, Célia. Diez palabras clave sobre Mujer. España: Navarra, 1995.

BOURDIEU, Pierre. A dominação masculina. Rio de Janeiro: Bertrand Brasil, 1999.

BRASIL. Presidência da República. Secretaria de Políticas para as Mulheres. Plano Nacional de Políticas para as Mulheres. Brasília: Secretaria de Políticas para as Mulheres, 2013.

CASIQUE, Irene. El complejo vinculo entre empoderamiento de la mujer y violência de género. In: CASTRO, Roberto; CASIQUE, Irene (Ed.). Estudios sobre cultura, género y violência contra las mujeres. Cuernavaca: UNAM; Centro Regional de Investigaciones Multidisciplinarias, 2007. p. 231-259. 


\section{temporalis}

FEMENÍAS, María Luisa. Esbozo de un feminismo latinoamericano. Revista Estudos Feministas, v. 15, n. 01, p. 11-25, jan./abr. 2007.

FERRER, Diana Valle. Espacios de liberdad: mujeres, violência domestica y resistencia. Buenos Aires: Espacio, 2011. Capítulo II - Raíces de la violência contra las mujeres: perspectivas teóricas. p. 37-68.

FOUCAULT, Michel. História da Sexualidade: a vontade de saber, v. I. 15. ed. Rio de Janeiro: Graal, 1988.

HUACUZ ELIAS, María Guadalupe. Violencia de Género o Violencia Falocentrica? variaciones sobre um sis/tema complexo. México: Instituto Nacional de Antropologia y Historia, 2009. (Coleción Cientifica, 546, Serie Antropologia).

LAGARDE, Marcela. Género y feminismo: desarrollo humano y democracia. Madrid: Horas \& Horas, 1996.

. Una Mirada feminista en el umbral del milenio. Costa Rica: Instituto de Estudios de la Mujer; Universidad Nacional, 1999.

LAMAS, Marta (Compil.). El Género: la construcción cultural de la diferencia sexual. México: Programa Universitario de Estudios de Género; Universidad Autónoma de México, 2003.

MANUEL, Teresa San Segundo (directora). Violencia de género: una visión multidisciplinar. Madrid: Editorial Centro de Estudios Ramón Aceres, 2008.

RODRIGUEZ, María Elena. Hijas de la igualdad, herederas de injusticias. Madrid: Narcea, 2008.

SCOTT, Joan. Gênero: uma categoria útil de análise histórica. Revista Educação \& Realidade, Porto Alegre, v. 20, n. 2, jul./dez. 1995.

VELÁZQUEZ, Susana. Violências Cotidianas, Violência de Gênero: escutar, compreender, ajudar. Buenos Aires: Paidós, 2006. 